Open Access

\title{
The Efficacy of Spirometry as a Screening Tool in Detection of Air Flow Obstruction
}

\author{
Nabeel Manzar, A. Suleman Haque*, Bushra Manzar and Muhammad Irfan
}

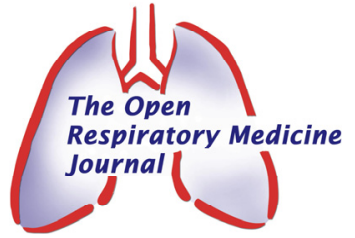

Aga Khan University Hospital \& Dow University of Health Sciences, Karachi, Pakistan

\begin{abstract}
Background/Objectives: In developing countries, spirometry has not been considered a part of routine medical check-up. The purpose of the study was to establish the usefulness of spirometry as a primary screening tool in detecting air flow obstruction (AFO) during routine medical check-up (RMC).

Methods: This was a hospital based, retrospective, non-randomized case series study of 3696 participants, who presented to hospital for routine medical check-up. All subjects were assisted at the Pulmonary Medicine Department, from January 2003 till December 2008 who, having met other inclusion criteria, underwent spirometry. Data were analyzed using proportion, group means, standard deviations and Pearson Chi Square test.
\end{abstract}

Results: The overall yield from spirometry in detecting AFO was 211 patients $(5.7 \%) ; 174$ males $(6.1 \%)$ and 37 females (4.4\%) $(\mathrm{P}=0.158$, Pearson Chi Square test). Greater age at presentation and BMI correlated significantly with AFO in the target group $(\mathrm{P}=<0.001 ; \mathrm{P}=<0.005)$ respectively. Dyspnoea was the most frequent symptomatology observed in those diagnosed with AFO.

Conclusion: These results suggest that spirometry during RMC for all persons can detect a significant number of patients with AFO particularly among the middle and older age groups with a low BMI.

Keywords: Spirometry, airflow obstruction, routine medical check-up, early screening, epidemiology.

\section{INTRODUCTION}

Air flow obstruction (AFO) is a universal health problem with a high morbidity and mortality rate such that the disease today presents a real public health problem and a major burden on health care facilities all around the world [1]. AFO particularly COPD at the moment is on the rise [2] in both developed and underdeveloped countries, moreover it has been projected to be the third leading cause of death globally by 2020 [3]. AFO today represents $90 \%$ of the patients with Chronic Obstructive Lung Disease (COPD). It is estimated that about $10 \%$ of the general population have the asymptomatic disease and $26 \%$ of the people above 45 years of age have indications of AFO $[4,5]$. However only a quarter of these are known to their physicians owing to the problem of early identification of the disease as well as late patient presentation in advanced stages $[5,6]$. In a study carried out by Fukuchi et al. in Japan [7], it was noted that $90.6 \%$ of the population with airflow obstruction were under diagnosed. Similarly in a community based research carried out by Pena et al. [8], 52\% of the British general population had not been diagnosed as having COPD.

Spirometry is an important diagnostic modality for monitoring and management of various respiratory diseases and represents the main diagnostic tool for COPD by measuring the AFO $[9,10]$. Nevertheless this diagnostic test

*Address correspondence to this author at the Section of Pulmonary \& Critical Care Medicine, Aga Khan University Hospital \& Dow University of Health Sciences, Karachi, Pakistan; Tel: +92-21-35685571; Fax: +92-2135685571; E-mail: nmanzar2003@hotmail.com continues to be used very little in primary care setting especially in developing countries [11].

Undiagnosed airflow obstruction due to non-usage of spirometry is common in the general population and is associated with impaired health status of the community especially in third world countries like Pakistan, where resources are limited and budgetary allocation to health inadequate. In this scenario our study carries huge implications for revolutionizing primary health care as spirometry has till date not been completely considered a part of routine medical examination despite the high burden of respiratory obstructive diseases. This could potentially be due to the fact that very few studies to evaluate the role of spirometry have been carried out in the context of the local population in underdeveloped countries where the prevalence of COPD is not known. The primary objective of our study was to establish the efficacy of spirometry in determining the prevalence of AFO in subjects of Asian origin to recommend it for all people on RMC.

\section{METHODS}

This hospital based, retrospective, non-randomized and non-interventional case series study was carried out at Pulmonary Medicine department, Aga Khan University Hospital, Karachi, Pakistan beginning from January 2003 till December 2008. A total of 3696 participants presenting to hospital for routine medical check up were enrolled in the study according to the set out inclusion criteria. The study was carried out in accordance with the declaration of Helsinki of 1975 as revised in 1983. The primary outcome measure was the evaluation of spirometry in detecting air flow obstruction on routine medical checkup. 
Only those patients fulfilling the following set out criteria were enrolled in the study:

1. Those who gave consent for participating in the study.

2. Participants of all ages and gender as determined by filled Performa with a definite history of symptomatology and demographic information.

\section{Supervised Spirometry by a qualified technician.}

Patients with the following pathologic state or problems were excluded from the study:

1. Previously diagnosed cases of Asthma, COPD or any other respiratory disease.

2. Abnormalities on chest X-ray like hyperinflation, hyperlucency of the lungs, and rapid tapering of the vascular markings.

3. Did not undergo Spirometry.

AFO was defined according to GOLD guidelines 2006, in which $\mathrm{FEV}_{1} \%$ is $70 \%$ or less. According to our followed criteria $\mathrm{FEV}_{1} \%$ is the ratio of Forced Expiratory Volume $\left(\mathrm{FEV}_{1}\right)$ to Forced Vital Capacity (FVC) [10]. The study was carried out in two parts, first the participants were made to fill out a well structured questionnaire regarding their baseline demographics like weight, height and symptomatology, followed by pulmonary function tests administered using a flow type spirometer by a well trained and experienced laboratory technologist according to published data and GOLD guidelines for vital capacity (VC), forced vital capacity (FVC) and forced expiratory volume in one second $\left(\mathrm{FEV}_{1}\right)$ to reduce any recruitment bias i.e. regression to mean. These parameters were obtained from the best of each curve recorded for the maximal inspiration, maximal slow expiration, maximal inspiration and maximal forced expiration procedures meeting American Thoracic Society (ATS) acceptability and repeatability criteria [12]. The investigators performed regular calibration checks.

Classification of subjects was done according to age, sex, BMI and symptomatology criteria. If the subject underwent several medical checkups during our study period, the latest data was used for analysis. The prevalence of AFO was the ratio of persons with $\mathrm{FEV}_{1} \%$ less than $70 \%\left(\mathrm{FEV}_{1} / \mathrm{FVC} \leq 70\right)$ respectively. Subjects were divided into three age groups (1) $\leq 35$ years in age (2) between 36-55 years and (3) >55years. Subjects were divided into four groups with respect to BMI according to WHO criteria [13]: (1) $<18.5 \mathrm{Kg} / \mathrm{m}^{2}$ (Under Wt) (2) $18.5-22.9 \mathrm{Kg} / \mathrm{m}^{2}$ (Normal) (3) $23-24.9 \mathrm{Kg} / \mathrm{m}^{2}$ (Over Wt) (4) $>25 \mathrm{Kg} / \mathrm{m}^{2}$ (Obese). BMI was calculated as body weight expressed in kilograms divided by the square of body height in meters.

Data for physical and respiratory variables were expressed as means \pm standard deviation (S.D). The prevalence of AFO was characterized by age, sex, BMI and symptomatology of the subjects. In our study all the data was collected on medical check ups. Data were entered in Statistical Package for Social Sciences (SPSS version 16) and analysis of the data was done using frequencies, proportions, group means, standard deviations and Pearson Chi Square test. Alpha level of 0.05 , power of 0.8 and Confidence interval of $95 \%$ were selected for analysis.

\section{RESULTS}

A total of 3696 subjects based on the inclusion criteria were incorporated in the study. 2861 males (77\%) and 835 females $(23 \%)$ aged between 5 and 90 years (mean \pm std. $\mathrm{dev}=47 \pm 13$ years) were included in the study. The male to female ratio was $3.4: 1$ with a mean height of $163+/-78 \mathrm{~cm}$, weight of $77.6+/-101.5 \mathrm{~kg}$ and $\mathrm{FEV}_{1} \%$ of $85+/-136$. The baseline characteristics of subjects of each age and sex group are presented in Table $\mathbf{1}$.

Out of the total cohort of subjects, 787 participants $(21.3 \%)$ were $\leq 35$ yrs in age, 1989 were between 36-55 years $(53.8 \%)$ and 920 were $>55$ years of age $(24.9 \%)$. The overall yield from spirometry in detecting AFO was 211 patients $(5.7 \%)$. One hundred and seventy four males $(6.1 \%)$ out of 2861 total males and 37 females (4.4\%) out of 835 total females suffered from AFO according to GOLD guidelines. One hundred and thirty seven patients had mild degree of AFO while 46 and 28 patients suffered from moderate and severe AFO respectively. None of the subjects had very severe AFO; however 549 subjects were in the restrictive spirometry group. In most age groups, there was a

Table 1. Baseline Characteristics of Participants

\begin{tabular}{|c|c|c|c|c|c|}
\hline \multirow{2}{*}{ Variables } & \multirow{2}{*}{ Sex } & \multicolumn{3}{|c|}{ Age Groups (Mean \pm std.dev) } & \multirow{2}{*}{ Total } \\
\hline & & $<35$ Years & 36-55 Years & $>55$ Years & \\
\hline \multirow{2}{*}{$\mathrm{N}(\%)^{*}$} & $\mathrm{M}$ & $657(84)$ & $1536(77)$ & $668(73)$ & $2861(77)$ \\
\hline & $\mathrm{F}$ & $123(16)$ & $460(23)$ & $252(27)$ & $835(23)$ \\
\hline \multirow{2}{*}{ Weight (kg) } & $\mathrm{M}$ & $94 \pm 400$ & $81 \pm 15$ & $77 \pm 14$ & $83 \pm 192$ \\
\hline & $\mathrm{F}$ & $63 \pm 18$ & $70 \pm 14$ & $70 \pm 17$ & $69 \pm 16$ \\
\hline \multirow{2}{*}{ Height $(\mathrm{cm})$} & M & $174 \pm 325$ & $170 \pm 10$ & $168 \pm 8$ & $171 \pm 114$ \\
\hline & $\mathrm{F}$ & $156 \pm 16$ & $156 \pm 9$ & $154 \pm 10$ & $155 \pm 11$ \\
\hline \multirow{2}{*}{$\operatorname{BMI}\left(\mathrm{kg} / \mathrm{m}^{2}\right)$} & M & $34 \pm 144$ & $30 \pm 69$ & $27 \pm 7$ & $30 \pm 86$ \\
\hline & $\mathrm{F}$ & $38 \pm 129$ & $29 \pm 14$ & $31 \pm 23$ & $31 \pm 52$ \\
\hline \multirow{2}{*}{$\mathrm{FEV}_{1} \%(\%)$} & M & $85 \pm 7$ & $83 \pm 7$ & $79 \pm 10$ & $83 \pm 8$ \\
\hline & $\mathrm{F}$ & $88 \pm 6$ & $102 \pm 386$ & $82 \pm 8$ & $94 \pm 287$ \\
\hline
\end{tabular}

N: Number of subjects; BMI: Body Mass Index; FEV1\%: Percentage of Forced Expiratory Volume (FEV) in one second for Forced Vital Capacity (FVC).

*The figures have been rounded to the nearest zero. 
trend of higher prevalence of AFO in males as compared to females, however statistical significance could not be reached $(\mathrm{P}=0.158$, Pearson Chi square Test $)$. The distribution of AFO by age was significantly related with 19 subjects in those $\leq 35$ years of age $(2.4 \%), 79$ subjects in those between $36-55$ years $(3.9 \%)$ and 113 in those $>55$ years $(12.3 \%)$ (Table 2 ).

Table 2. Prevalence of COPD in Participants in Relation to Age, Sex \& BMI

\begin{tabular}{|l|c|c|c|}
\hline \multirow{2}{*}{ Variables } & \multicolumn{2}{|c|}{ FEV $_{\mathbf{1}} \% \mathbf{~ N}(\%)$} & \multirow{2}{*}{ P-Value } \\
\cline { 2 - 3 } & $\leq \mathbf{7 0} \%$ & $>\mathbf{7 0} \%$ & \\
\hline \hline $\begin{array}{l}\text { Age Groups } \\
\leq 35\end{array}$ & $19(2)$ & $768(98)$ & \\
$36-55$ & $79(4)$ & $1910(96)$ & $<0.001$ \\
$>55$ & $113(12)$ & $807(88)$ & \\
\hline Sex & & & \\
Male & $174(6)$ & $2687(94)$ & \multirow{2}{*}{0.158} \\
Female & $37(4)$ & $798(96)$ & \\
\hline BMI & & & \\
$<18.5$ (Under Wt) & $11(9.8)$ & $101(90.2)$ & \\
18.5 -22.9(Normal) & $49(8.7)$ & $516(91.3)$ & \\
$23-24.9$ (Over Wt) & $34(5.9)$ & $544(94.1)$ & \\
$>25$ (Obese) & $117(4.8)$ & $2324(95.2)$ & \\
\hline
\end{tabular}

${ }^{*} \mathrm{FEV}_{1} \%$ is the ratio of Forced Expiratory Volume $\left(\mathrm{FEV}_{1}\right)$ to Forced Vital Capacity $(\mathrm{FVC})$, The figures have been rounded to the nearest zero.

'Pearson Chi square test.

There was no significant difference in the mean values of BMI across various age groups (Table 1). Out of the total subjects, 3019 participants (81.7\%) had a BMI above normal i.e. above $23 \mathrm{Kg} / \mathrm{m}^{2}$. However the highest prevalence of AFO was seen in the underweight group followed by normal, overweight and obese group respectively. The prevalence of COPD was significantly related to decreasing BMI $(\mathrm{P}=0.006)$. Table 2 presents a comparison of BMI and AFO.

Out of the 211 patients having $\mathrm{FEV}_{1} \%$ less than $70 \%, 95$ subjects suffered from dyspnoea (45\%), 66 from chronic cough $(31.3 \%), 61$ from expectorant cough with sputum discharge $(28.9 \%), 33$ from wheeze $(15.6 \%)$. All the symptoms were significantly related with AFO $(\mathrm{P}=<0.001)$, however there were no patients with complains of chest pain $(\mathrm{P}=1.00)$. Presenting symptomatology in subjects and its relation to COPD is shown in Table 3.

\section{DISCUSSION}

The present study sought to investigate the efficacy of spirometry in determining the prevalence of $\mathrm{AFO}$ as gauged by $\mathrm{FEV}_{1} / \mathrm{FVC}\left(\mathrm{FEV}_{1} \%\right) \leq 70 \%$ in the Pakistani population of Asian origin, where a low screening rate for COPD persists despite the consensus in the medical community about the potential harmful effects of AFO particularly COPD on health if not prevented and treated in the early stages of the disease. The present study was motivated by the invariably late presentation and occurrence of AFO not only in Pakistan but world over [14].

The prevalence of AFO in the study was $5.7 \%$. In a cross sectional study carried out in the Spanish population, Jaén
Díaz et al. [15] estimated a prevalence in $16.4 \%$ of the population. In another community based project Takemura et al. [16] observed a prevalence of $3.6 \%$ in all subjects of Japanese origin without Bronchodilator Reversibility Testing. However comparison between our study and others is likely to be biased attributed to the different study population, setting and criteria used for assessing AFO and COPD. Age was significantly related to COPD in the study, with rising cases of AFO with increased age groups. Similar conclusions have been drawn from numerous studies carried through out the globe $[15,16]$. Gender was not related to AFO in the target group, presumably due to the fact that women in Pakistan are most of the time housewives whereas men are commonly exposed to occupational and environmental respiratory hazards leading to AFO.

Table 3. Symptomatology Observed in Participants on Presentation

\begin{tabular}{|c|c|c|c|}
\hline \multirow{2}{*}{ Symptom } & \multicolumn{2}{|c|}{ FEV $_{\mathbf{1}} \% \mathbf{~ N ~ ( \% )}$} & \multirow{2}{*}{ P-Value $^{\mathbf{*}}$} \\
\cline { 2 - 3 } & $\leq \mathbf{7 0} \%$ & $>\mathbf{7 0} \%$ & \\
\hline \hline \multirow{2}{*}{ Dyspnoea } & $\begin{array}{c}95 \\
(45)\end{array}$ & $\begin{array}{c}817 \\
(23.5)\end{array}$ & $<0.001$ \\
\hline \multirow{2}{*}{ Cough } & $\begin{array}{c}66 \\
(31.3)\end{array}$ & $\begin{array}{c}550 \\
(15.8)\end{array}$ & $<0.001$ \\
\hline \multirow{2}{*}{ Sputum } & $\begin{array}{c}61 \\
(28.9)\end{array}$ & $\begin{array}{c}497 \\
(14.3)\end{array}$ & $<0.001$ \\
\hline Wheeze & 33 & 226 & $<0.001$ \\
& $(15.6)$ & $(6.5)$ & \\
\hline \multirow{2}{*}{ Chest pain } & $\begin{array}{c}0 \\
(0.0)\end{array}$ & $\begin{array}{c}2 \\
(0.1)\end{array}$ \\
\hline
\end{tabular}

${ }^{*} \mathrm{FEV}_{1} \%$ is the ratio of Forced Expiratory Volume $\left(\mathrm{FEV}_{1}\right)$ to Forced Vital Capacity (FVC), For the sake of simplicity the data of only those subjects with positive symptomatology is shown.

${ }^{\circ}$ Pearson Chi Square test.

Smoking is a recognized risk factor for $\mathrm{AFO}$ and smoking rates provide a valuable method of estimating AFO prevalence in the general population. We assumed the smoking prevalence to be that of the general population $(22 \%)[17,18]$ and the rate of AFO in smokers to be around $15-20 \%$ in line with international studies $[19,20]$. On the basis of these statistics the prevalence of AFO in smokers for our set of population comes out to be highly significant.

COPD has been linked with a chronic state of inflammation which may be due to the release of inflammatory mediators like C-reactive protein (CRP) [21]. Chronic state of inflammation is associated with weight loss, muscle wasting and tissue depletion [22, 23]. In our study eleven subjects out of $112(9.8 \%)$ in the underweight category were suffering from AFO while 117 subjects out of $2441(4.8 \%)$ in the obese category were suffering from AFO. This increased prevalence of AFO in the underweight category has been documented by other studies around the globe as well [21, 24, 25]. In a recent research carried out by Melbye et al., [26] a strong link was recognized between bronchial airflow limitation and the circulating CRP level in an elderly population. On the other hand in a study conducted by Nguyen et al. [27], it was established that CRP 
levels almost double with the rise in weight class. A relationship between COPD and BMI is increasingly being recognized, although the nature of this association to date remains unknown [28] hence these results should be interpreted with potential caution until a definite relationship has been proved.

Dyspnoea was found in the majority of the subjects diagnosed with AFO (45\%). In a study conducted by Kömüs et al. [29], cough was found to be the predominant symptom in $77.6 \%$ of the population included in the at risk group while dyspnoea was the second most prevalent symptom in $62.1 \%$ of the population. Similarly in another study conducted by Kornmann et al. [30], 84\% of the patients diagnosed with COPD had cough followed by $70 \%$ of the patients suffering from exertional dyspnoea. The positive predictive value of other symptoms like cough, sputum discharge or wheeze were comparatively less than dyspnoea in our study, however previous studies carried out note the importance of simultaneous presence of two or more symptoms, as these symptoms almost double the chances of a positive diagnosis of AFO [31].

All the participants included in our study were those who came for general medical checkup and had no prior history of AFO, then only were they referred for spirometry by the primary care physician; this helped us to remove any selection bias due to selection of subjects already suffering from AFO. The sample size involved was potentially large enough, however due to non-representative nature of the sample as well as being a hospital based study we cannot generalize the results of our study for the whole country based upon the existing statistics. Further more bronchodilation was not carried out to check reversibility. Despite these limitations the study gives an idea of the burden of unrecognized and hidden prevalence of AFO in the country due to its late presentation and holds important implications for policy makers for the future and will help them determine what future strategies and planning need to be undertaken to tackle this problem at the grass root level.

In conclusion, this study fulfills the objectives set by the study protocol for this project of assessing the various risk factors and the efficacy of spirometry in determining the prevalence of AFO in the population and advocates the use of early screening tests like spirometry for prevention and management of life threatening complications in AFO population. This study holds important implications for public health and highlights the high prevalence of undiagnosed AFO in the target population particularly those in higher age group with a low BMI.

\section{AUTHORS CONTRIBUTION STATEMENT}

NM, ASH, MI conceived the study, participated in its design and coordination. ASH \& MI performed the data collection and statistical analysis. NM \& BM drafted the manuscript. BM participated in the design of the study. All the authors read and approved the final manuscript.

\section{REFERENCES}

[1] Antó JM, Vermeire P, Vestbo J, et al. Epidemiology of chronic obstructive pulmonary disease. Eur Respir J 2001; 17: 982-94.

[2] Holt K. Improving early detection of COPD: the role of spirometry screening assessment. Prof Nurse 2004; 20(3): 31-3.
[3] Murray CJL, Lopez AD. Alternative projections of mortality and disability by cause 1990-2020: global burden of disease study. Lancet 1997; 349: 1498-1504.

[4] Renwick DS, Conolly MJ. Prevalence and treatment of chronic airways obstruction in adults over the age of 45 . Thorax 1996; 51: 164-8.

[5] Tirimanna PRS, Schayck CP van, Otter JJ den, et al. Prevalence of asthma and COPD in general practice in 1992: has it changed since 1977? Br J Gen Pract 1996; 46: 277-81.

[6] Siafakis NM, Vermeire P, Pride NB, et al. ERS-consensus statement. Optimal assessment and management of chronic obstructive pulmonary disease (COPD). Eur Respir J 1995; 8: 1398-1420.

[7] Fukuchi Y, Nishimura M, Ichinose $\mathrm{M}$ et al. COPD in Japan: the Nippon COPD epidemiology study. Respirology 2004; 9: 458-65.

[8] Pena V S, Miravitlles M, Gabriel R, et al. Geographic variations in prevalence and underdiagnosis of COPD: results of the IBERPOC multicentre epidemiological study. Chest 2000; 118: 981-9.

[9] Hassan SH, Sheikh SA, Munfeat F. Spirometry and vital parameters in assessment of asthma and COPD in rural population of Karachi. Pak J Chest Med 2007; 13(1): 15-20.

[10] Buist AS. GOLD Executive and Scientific Committee. Global strategy for the diagnosis, management and prevention of chronic obstructive pulmonary disease 2006. Global Initiative for Chronic Obstructive Lung Disease (GOLD). [online] 2009 Available from : URL: http://www.goldcopd.org

[11] van den Berg JW, van der Molen T, Kerstjens HA et al. Comments on screening spirometry for detection of COPD. Ned Tijdschr Geneeskd 2007; 151(28): 1557-60.

[12] American Thoracic Society Standardization of Spirometry, 1994 Update. Am J Respir Crit Care Med 1995; 152: 1107-36.

[13] WHO expert consultation. Appropriate body-mass index for Asian populations and its implications for policy and intervention strategies. Lancet 2004; 363: 157-63.

[14] National Heart, Lung and Blood Institute. Global initiative for chronic obstructive lung disease. NIH publication No. 2071. 2001.

[15] Jaén Díaz JI, de Castro Mesa C, Gontán García-Salamanca MJ, López de Castro F. Prevalence of chronic obstructive pulmonary disease and risk factors in smokers and ex-Smokers. Arch Bronconeumol 2003; 39: 554-8.

[16] Takemura H, Hida W, Sasaki T, et al. Prevalence of chronic obstructive pulmonary disease in Japanese people on medical check-up. Tohoko J Exp Med 2005; 207: 41-50.

[17] Alam S. Prevalence and pattern of smoking in Pakistan. J Pak Med Assoc Mar 1998; 48(3): 64-6.

[18] Ahmed R, Rashid R, Mcdonald PW, Ahmed W. Prevalence of cigarette smoking among young adults in Pakistan. J Pak Med Assoc 2008; 58(11): 597-601.

[19] Fletcher, C, Peto, R, Tinker, C, et al. The natural history of chronic bronchitis and emphysema: an eight-year study of early chronic obstructive lung disease in working men in London. Oxford, UK: Oxford University Press 1976.

[20] Surgeon General of the United States. The health consequences of smoking: chronic obstructive lung disease. Washington, DC: Surgeon General of the United States, 1984; Department of Health and Human Services Publication No. 84-50205.

[21] Karadag F, Kirdar S, Karul AB, Ceylan E. The value of C-reactive protein as a marker of systemic inflammation in stable chronic obstructive pulmonary disease. Eur J Intern Med 2008; 19(2): 1048.

[22] Wouters EF, Creutzberg EC, Schols AM. Systemic effects in COPD. Chest 2002; 121(5 Suppl): 127S-130S

[23] Wüst RC, Degens H. Factors contributing to muscle wasting and dysfunction in COPD patients. Int J Chron Obstruct Pulmon Dis 2007; 2(3): 289-300.

[24] Li HL, Xu B, Zheng W, et al. Epidemiological characteristics of obesity and its relation to chronic diseases among middle aged and elderly men. Zhonghua Liu Xing Bing Xue Za Zhi 2010; 31(4): 370-4.

[25] Yang L, Zhou M, Smith M, et al. Body mass index and chronic obstructive pulmonary disease-related mortality: a nationally representative prospective study of 220000 men in China. Int J Epidemiol 2010. [Epub ahead of print].

[26] Melbye H, Halvorsen DS, Hartz I, et al. Bronchial airflow limitation, smoking, body mass index, and statin use are strongly 
associated with the C-reactive protein level in the elderly. The Tromsø Study 2001. Respir Med 2007; 101(12): 2541-9.

[27] Nguyen XM, Lane J, Smith BR, et al. Changes in inflammatory biomarkers across weight classes in a representative US population: a link between obesity and inflammation. J Gastrointest Surg 2009; 13(7): 1205-12.

[28] Franssen FM, O'Donnell DE, Goossens GH, et al. Obesity and the lung: 5. Obesity and COPD. Thorax 2008; 63(12): 1110-7.
[29] Kömüs N, Tertemiz KC, Sevinç C. The importance of the at risk COPD patients (Stage 0) and clinical differences. Tuberk Toraks 2008; 56(4): 382-9.

[30] Kornmann O, Beeh KM, Beier J, et al. Newly diagnosed chronic obstructive pulmonary disease. Clinical features and distribution of the novel stages of the Global Initiative for obstructive lung disease. Respiration 2003; 70(1): 67-75.

[31] Medbø A, Melbye $H$. What role may symptoms play in the diagnosis of airflow limitation? A study in an elderly population. Scand J Prim Health Care 2008; 26(2): 92-8.

(C) Manzar et al.; Licensee Bentham Open.

This is an open access article licensed under the terms of the Creative Commons Attribution Non-Commercial License (http://creativecommons.org/licenses/ by-nc/3.0/) which permits unrestricted, non-commercial use, distribution and reproduction in any medium, provided the work is properly cited. 